\title{
In Vitro Evaluation of Microleakage of a Flowable Composite in Class V Restorations
}

\author{
Daniela Thomazatti CHIMELLO \\ Michelle Alexandra CHINELATTI \\ Renata Pereira RAMOS \\ Regina Guenka PALMA DIBB \\ Department of Restorative Dentistry, Faculty of Dentistry of Ribeirão Preto, University of São Paulo, \\ Ribeirão Preto, SP, Brazil
}

\begin{abstract}
The aim of this study was to evaluate microleakage around class $\mathrm{V}$ restorations using a flowable composite compared to a hybrid composite. Forty class V cavities were prepared on buccal and lingual surfaces of 20 human teeth, with occlusal and cervical margins at the enamel and cementum/dentin levels, respectively. Specimens were divided into 2 groups with 10 samples each. Group 1: buccal cavities received Paama 2 (conventional bonding agent) + Wave (flowable composite); lingual cavities were restored with Paama $2+$ Glacier (hybrid composite). Group 2: buccal cavities received Optibond Solo (self-priming bonding agent) + Wave; lingual cavities were restored with Optibond Solo + Glacier. After being stored in distilled water and finished, the teeth were thermocycled, immersed in a 50\% silver nitrate solution and embedded in resin. They were sectioned and the depth of tracer penetration was scored. The results were analyzed using Kruskall-Wallis and Wilcoxon tests. The restorations with flowable composite and those with hybrid composite from the same group showed similar results of microleakage for both occlusal and cervical margins. Optibond Solo improved the sealing of the restorations when compared with Paama $2(\mathrm{p}<0.01)$. None of the restorative materials completely sealed the tooth/ restoration interface at the cervical margins.
\end{abstract}

Key words: flowable composite, microleakage, composite resin.

\section{INTRODUCTION}

In the age of esthetic dental adhesives, new materials and, consequently, new techniques have been developed for tooth restoration, offering special handling characteristics and seeking to facilitate the daily practice of the clinician. In an attempt to improve the adaptability of the restorative materials, a new type of composite resin was developed, differing from traditional composites. These new composites have low viscosity and high flowability. This allows the material to adapt closely to the microstructural and macrostructural defects in the floor and walls of the cavity, resulting in an improvement of the tooth/restoration union resistance (1). The first generation of flowable composites, introduced in the mid-90s, has been indicated for several adhesive restoring procedures, such as class $\mathrm{V}$ restorations (2).
One of the concerns about the clinical longevity of composite resins is the great possibility of microleakage at the tooth/restoration interface (3-6). This lack of adaptation may occur partly due to polymerization contraction and extreme temperatures in the oral cavity (thermocycling), which may break the adhesion between the adhesive system and the cavity walls, forming microgaps $(3,4,6)$. Such gaps allow the penetration of microorganisms, fluids and chemical substances from the oral environment along the tooth/restoration interface (6), which may result in postoperative sensitivity $(2,3,5-8)$, marginal deterioration, recurrent caries and pulp injury $(3,6,9)$.

Marginal adaptation becomes even more difficult in class V cavities where there is little or no enamel at the cervical margins, and the restoration comes in contact with cementum. This decreases adhesion considerably, facilitating the dislodgment of the material

Correspondence: Profa. Dra. Regina Guenka Palma Dibb, Departamento de Odontologia Restauradora, Faculdade de Odontologia de Ribeirão Preto, USP, Av. do Café, s/n, Monte Alegre, 14040-904 Ribeirão Preto, SP, Brasil. Tel: +55-16-602-4078. Fax: +55-16-633-0999. e-mail: rgpalma@forp.usp.br 
towards occlusal during polymerization, because adhesion of a composite resin to enamel surface is better when compared to dentin surface (3).

The amount of matrix can influence the degree of polymerization contraction (10). The flowable composites have a lower percentage of inorganic filler, and therefore a higher percentage of matrix than the traditional hybrid composites (providing high fluidity). Thus, it could be thought that they could contract more during polymerization and create more tension in the union agents than the traditional composites, resulting in greater microleakage (2). On the other hand, some authors have theorized that because of the low modulus of elasticity and the increased bond strength presented by the flowable composites, there may be less polymerization shrinkage $(1,6,10)$.

The objective of this in vitro study was to evaluate microleakage in class $\mathrm{V}$ restorations, which were restored with a flowable composite compared to a traditional hybrid resin (used as a control). Two types of smear-layer-removing adhesive systems were used.

\section{MATERIAL AND METHODS}

Twenty human canines and premolars, extracted in a period of six months, were selected. After being stored in saline solution at room temperature, teeth surfaces were cleaned with pumice stone and water.

Two class $\mathrm{V}$ cavities were prepared in each tooth, one in the buccal surface and the other in the lingual surface, with occlusal margins at the enamel and cervical margins at the cementum/dentin level. Dimensions of the cavities were $3 \mathrm{~mm}$ wide, $2 \mathrm{~mm}$ high, and $2 \mathrm{~mm}$ deep, prepared with a FG 329 carbide bur (Beavers Dental Division of Sybron Canada Ltd., Ontario, Canada) in a water-cooled high-speed handpiece. Cavities were finished with burs in a low-speed handpiece and manual sharp instruments. They also received a 0.5 $\mathrm{mm}$ wide bevel at a $45^{\circ}$ angle on their occlusal margins with a diamond bur. Cervical margins ended at a $90^{\circ}$ angle with the longitudinal surface of the teeth.

The specimens were divided into two groups of 10 teeth each. The cavities were restored according to manufacturer recommendations. Group 1 - Paama 2 (Primer batch \#61107, Adhesive batch \#60707, Southern Dental Industries, Bayswater, Australia) + Wave (batch \#70741, Southern Dental Industries), and Paama 2 + Glacier (batch \#60912, Southern Dental Indus- tries): The total-etch technique was used on enamel and cementum/dentin surfaces, with $37 \%$ phosphoric acid (Southern Dental Industries) for $20 \mathrm{~s}$. The acid was applied initially to the enamel margins and then extended from the superficial to deep dentin. After application of the acid gel, the substrate was washed with an air/water spray for $20 \mathrm{~s}$ and excess humidity was removed by an absorbent paper applied on the dentin. Five coats of primer were applied on the etched surface with a brush. A thin, uniform coating of adhesive was applied on the primed surface and light-cured for $20 \mathrm{~s}$ (Ultralux Electronic, Dabi Atlante, Ribeirão Preto, SP, Brazil), with the light-unit calibrated with $400 \mathrm{~mW} / \mathrm{cm}^{2}$. The flowable composite (Wave) was inserted with the needle provided by the manufacturer into the buccal preparations by an incremental technique, and each increment was light-cured for $30 \mathrm{~s}$. The traditional hybrid composite (Glacier) was used to restore the lingual preparations. Glacier was applied into the cavities with an instrument and each increment was light-cured for $40 \mathrm{~s}$. Group 2 - Optibond Solo (batch \#707225, Kerr Corporation, Orange, CA, USA) + Wave, and Optibond Solo + Glacier: Dentin and enamel surfaces were etched for $15 \mathrm{~s}$ with $37 \%$ phosphoric acid (first applied to the enamel margins and then extended to the dentin), washed with an air/water spray for $15 \mathrm{~s}$, and dried with absorbent paper applied lightly on dentin without desiccation. A thin layer of Optibond Solo adhesive system was applied on enamel and cementum/ dentin surfaces, with light brushing motion for $15 \mathrm{~s}$, and light-cured for $20 \mathrm{~s}$. A second layer was applied and light-cured for another $20 \mathrm{~s}$. The subsequent restoring procedures were the same as described for group 1.

The teeth were maintained in distilled water for $24 \mathrm{~h}$ at $37^{\circ} \mathrm{C}$. After this period, the restorations were finished and polished with Sof-Lex sequential disks (3M do Brasil Ltd., Sumaré, SP, Brazil). The teeth were thermocycled (Ética Equipamentos Científicos S.A., São Paulo, SP, Brazil $) 600$ times $\left(4^{\circ} \mathrm{C}-55^{\circ} \mathrm{C}\right)$, with a dwell time of $30 \mathrm{~s}$.

After thermocycling, coronary and radicular surfaces of the teeth, except the restorations and $1 \mathrm{~mm}$ around their margins, were isolated with two layers of nail varnish. The apexes of the teeth received four layers of nail varnish, to avoid penetration of the tracer towards the pulp. The teeth were immersed in a $50 \%$ silver nitrate solution (laboratory-manipulated) for $8 \mathrm{~h}$ (5), washed in running water and embedded in color- 
less acrylic resin (Artigos Odontológicos Clássico Ltda., São Paulo, SP, Brasil) (11).

The specimens were sectioned longitudinally in a buccal-lingual plane with a water-cooled diamond saw (Minitom-Struers, Copenhagen, Denmark); each section was $1 \mathrm{~mm}$ thick, and each restoration had 3 sections. The sections were exposed to a photoflood lamp (Silvânia) for the sensibilization of the tracer, and examined under an optic microscope (Nikon, Japan) at 40X magnification by 3 examiners who were previously calibrated. Both sides of each section were examined, and the marginal infiltration of the tracer was classified according to the following criteria: score 0 : without evidence of infiltration in the tooth/restoration interface; score 1: infiltration of the tracer in up to $1 / 3$ of the walls of the restoration; score 2: infiltration of the tracer in more than $1 / 3$ of the walls of the restoration, without reaching the axio-cervical or axio-occlusal angles; score 3: infiltration of the tracer reaching the axio-cervical or axio-occlusal angles and going towards the pulp.

Statistical analysis of the results was obtained by the Kruskall-Wallis test (comparing the adhesives and the restorative materials) and the Wilcoxon test (comparing the occlusal and cervical margins).

\section{RESULTS}

The data related to the degree of microleakage at occlusal (enamel) and cervical margins (cementum/ dentin) of the 2 groups are reported in Table 1 . The restorations with the flowable composite and those with the hybrid composite from the same group had similar results of microleakage for both occlusal and cervical margins. However, the restorations with the flowable composite from group 2 presented less microleakage than the restorations with the same material from group $1(\mathrm{p}<0.05)$. Similarly, the restorations with the hybrid composite from group 2 leaked less than the restorations with the same material from group 1 ( $p<0.05)$. In most of the sections, the cervical margins presented more microleakage than the occlusal margins $(\mathrm{p}<0.01)$.

\section{DISCUSSION}

One of the factors that contributes to marginal microleakage in restorations with composite resins is the contraction that the material suffers during polymerization $(3,4,12)$. Thermocycling may also contribute to the dislodgment of the restoration from the cavity walls (3), although an in vivo study demonstrated that mastication had a greater influence on the marginal integrity of composite restorations than did thermal stress (11). Polymerization contraction may cause a break in the adhesion between the tooth and restorative material, resulting in microscopic gaps in the tooth/ restoration interface $(3,4,12)$. Thermocycling causes contraction and expansion of the tooth and the restoration, and because they have different coefficients of thermal expansion, the adhesion between them may be broken $(3,8)$.

Microleakage is more critical in margins with little or no enamel, which characterizes most of the noncarious class $\mathrm{V}$ cavities (7). The cervical margins of such restorations may be at cementum or dentin surfaces. The adhesion between composites and dentin is not as strong as with enamel, therefore the material can be dislodged towards occlusal during polymerization contraction, causing a bad adaptation of the restoration at the cervical margins (3).

In the present study, when comparing the cervical and the occlusal margins of the restorations, the cervical margins of most samples showed the greatest

Table 1. Distribution of microleakage scores along occlusal and cervical margins.

\begin{tabular}{|c|c|c|c|c|}
\hline & \multicolumn{4}{|c|}{ Microleakage } \\
\hline & 0 & 1 & 2 & 3 \\
\hline \multicolumn{5}{|l|}{ Enamel Margins } \\
\hline \multicolumn{5}{|l|}{ Paama 2} \\
\hline + Wave & 10 & 0 & 0 & 0 \\
\hline + Glacier & 10 & 0 & 0 & 0 \\
\hline \multicolumn{5}{|l|}{ Optibond } \\
\hline + Wave & 10 & 0 & 0 & 0 \\
\hline + Glacier & 9 & 0 & 1 & 0 \\
\hline \multicolumn{5}{|l|}{ Cervical Margins } \\
\hline \multicolumn{5}{|l|}{ Paama 2} \\
\hline + Wave & 0 & 2 & 5 & 3 \\
\hline + Glacier & 0 & 1 & 9 & 0 \\
\hline \multicolumn{5}{|l|}{ Optibond } \\
\hline + Wave & 1 & 6 & 1 & 2 \\
\hline + Glacier & 3 & 4 & 2 & 1 \\
\hline
\end{tabular}

$\mathrm{N}=10$ in each group $\mathrm{p}<0.05$. 
scores of microleakage, what is in agreement with the literature $(3,7,13)$. When comparing the flowable composite with the hybrid resin from the same group, where the same adhesive system was used, there was no statistically significant difference between them at cervical and occlusal margins in agreement with Mazer and Russell (14).

The incremental technique may have influenced the results as well as the low elastic modulus of the flowable composite and its adaptation to tooth structure that may also have contributed to a smaller polymerization contraction.

Differing from the present results, Ferdianakis (6) observed a better marginal sealing of a flowable composite in comparison with a combination of two traditional hybrid composites.

The present results showed that the restorations which had Optibond Solo as the adhesive system presented less microleakage than those with Paama 2. Optibond Solo, which was the only product that belonged to another company, showed better results, even though it was bonded to products from a different manufacturer. This result probably occurred because the two adhesive systems presented different adhesion forces to the substrate.

Flowable composites are relatively new materials and clinical studies still do not provide conclusive results of their performance in the oral environment, suggesting that long-term clinical trials are necessary.

According to the present results, we conclude that none of the restorative materials completely sealed the tooth/restoration interface at cervical margins.

\section{RESUMO}

Chimello DT, Chinelatti MA, Ramos RP, Palma Dibb RG. Avaliação in vitro da microinfiltração de uma resina composta flowable em restaurações classe V. Braz Dent J 2002;13(3):184187.

O objetivo deste estudo foi avaliar a microinfiltração ao redor de restaurações classe $\mathrm{V}$, utilizando-se uma resina composta flow em comparação com uma resina híbrida tradicional. Quarenta cavidades classe $\mathrm{V}$ foram preparadas nas superfícies vestibulares e linguais de 20 dentes humanos, estando as margens oclusal e cervical em esmalte e cemento/dentina, respectivamente. Os espécimes foram divididos em dois grupos com 10 amostras cada, empregando-se dois sistemas adesivos associados às duas resinas testadas, tendo a vestibular sido restaurada por um grupo e a lingual por outro. Os dentes foram restaurados de acordo com as especificações do fabricante e armazenados em água destilada, em estufa, por 7 dias. As restaurações receberam acabamento, e os dentes foram termociclados e imersos em solução de nitrato de prata a 50\%. Após secção, a profundidade do traçador foi medida, tendo os resultados sido analisados pelos testes de Wilcoxon e Kruskal-Wallis. Baseado nos resultados, observou-se que o Optibond Solo apresentou melhores resultados que o Paama 2 ( $\mathrm{p}<0,01)$, porém, nenhum dos materiais restauradores selou completamente a interface dente/restauração nas margens cervicais.

Unitermos: resina flow, microinfiltração, resina composta.

\section{REFERENCES}

1. Rada RE. The versatility of flowable composites. Dent Today 1998; 17:78-81.

2. Bayne SC, Thompson JY, Swift Jr EJ, Stamatiades P, Wilkerson M. A characterization of first-generation flowable composites. J Am Dent Assoc 1998;129:567-577.

3. Kaplan I, Harris EF, Mincer HH, Gilpatrick RO. Microleakage of glass ionomer cement and composite resin restorations in cut non-retentive preparations and pre-existing cervical erosion/abrasion lesions. J Tenn Dent Assoc 1993;73:24-28.

4. Trushkowsky RD, Gwinnett AJ. Microleakage of class V composite, resin sandwich, and resin-modified glass ionomers. Am J Dent 1996;9:96-99.

5. Alani AH, Toh CG. Detection of microleakage around dental restorations: a review. Oper Dent 1997;22:173-185.

6. Ferdianakis K. Microleakage reduction from newer esthetic restorative materials in permanent molars. J Clin Pediatr Dent 1998;22:221-229.

7. Yap AUJ, Lim CC, Neo JCL. Marginal sealing ability of three cervical restorative systems. Quintessence Int 1995;26:817-820.

8. Versluis A, Douglas WH, Sakaguchi RL. Thermal expansion coefficient of dental composites measured with Strain Gauges. Dent Mater 1996;12:290-294

9. Déjou J, Sindres V, Camps J. Influence of criteria on the results of in vitro evaluation of microleakage. Dent Mater 1996;12:342-349.

10. Unterbrink GL, Lienbenberg WH. Flowable resin composites as "filled adhesives": Literature review and clinical recommendations. Quintessence Int 1999;30:249-257.

11. Qvist V. The effect of mastication on marginal adaptation of composite restorations in vivo. J Dent Res 1983;62:904-906.

12. Munksgaard EC, Hansen EK, Kato H. Wall-to-wall polymerization contraction of composite resins versus filler content. Scand J Dent Res 1987;95:526-531.

13. Van Meerbeek B, Perdigão J, Lambrechts P, Vanherle G. The clinical performance of adhesives. J Dent 1998;26:1-20.

14. Mazer RB, Russell RR. The uses of flowable composite resin in class V restorations: microleakage evaluation. J Dent Res 1998;77:131. 